\title{
РЕЦЕНЗИИ
}

\section{В.В. Высокова}

\section{ЛОРД КЛАРЕНДОН, ИЛИ РАССУЖДЕНИЯ О ПОЛИТИЧЕСКОЙ МОРАЛИ. РЕЦЕНЗИЯ: СОКОЛОВ А.Б. КЛАРЕНДОН И ЕГО ВРЕМЯ. СТРАННАЯ ИСТОРИЯ ЭДВАРДА ХАЙДА: КАНЦЛЕРА И ИЗГНАННИКА. СПБ. : АЛЕТЕЙЯ, 2017. 472 с.}

\author{
Исследование выполнено при финансовой поддержке гранта Российского научного фонда, \\ проект № 19-18-00186 “"Культура духа” vs “Культура разума”: Интеллектуалы и Власть \\ в Британии и России в эпоху Перемен (XVII-XVIII вв.)».
}

\begin{abstract}
Рецензия посвящена новой монографии доктора исторических наук, декана исторического факультета Ярославского педагогического университета им. К.Д. Ушинского А.Б. Соколова «Кларендон и его время: странная история Эдварда Хайда: канцлера и изгнанника». В центре внимания - новая в отечественной историографии интерпретация Английской революции XVII в.: сквозь призму интеллектуальной биографии Эд. Хайда А.Б. Соколов впервые в новейшее время обращается к идеологии роялистского лагеря, а также создает обширную его портретную галерею.

Ключевые слова: Английская революция XVII в.; Т. Гоббс; лорд Кларендон; политическая мораль; Стюарты; Эд. Хайд.
\end{abstract}

Знаменательным событием в отечественной новистике последнего времени стала монография «Кларендон и его время» Андрея Борисовича Соколова. Автор хорошо известен своими исследованиями по истории Британии XVII-XVIII вв. [1], работами по методологии и историографии истории $[2,3]$, а также анализом зарубежных учебников по истории [4]. Показательным является выбор темы его исследования - биография Эдварда Хайда, лорда Кларендона (1609-1674), видного деятеля Реставрации, консервативного мыслителя и отца-основателя историографии Английской революции XVII в. А.Б. Соколов наконец-то смещает фокус внимания с представителей левого лагеря Английской буржуазной революции (М.А. Барг, Т.А. Павлова и др.) на лагерь кавалеров-роялистов. Подобный подход вполне может претендовать на роль «славной революции» в отечественном англоведении.

Автор ставит перед собой триединую задачу: вопервых, «понять мотивы, двигавшие поступками героя, уловить его психологический склад», выявить его собственное «я»; во-вторых, «дать читателю представление о времени, когда жил Хайд», в-третьих, показать портретную галерею современников главного героя и разорвать «круг имен, очерченный... советскими англоведами» (С. 13-15). По существу, мы имеем дело с «биографическим протоколом» лорда Кларендона в духе Ханны Арендт [5] - его интеллектуальной биографией. Этот подход заставляет автора все время обращать внимание на умолчания и особенности изложения лордом Кларендоном событий бурного XVII в. в им же самим оставленных текстах. Это такие сочинения Эдварда Хайда, как «История мятежа и гражданских войн», опубликованное посмертно его сыновьями в 1702 г., произведение «Размышления и рассуждения о псалмах Давида» (1727), над которым Хайд работал фактически всю жизнь, дабы «сформулировать духовные и нравственные уроки» в контексте политических и церковных конфликтов своего времени; третьим по значимости А.Б. Соколов называет его «АнтиГоббса», или сочинение «Краткий обзор и исследование опасных и вредных для церкви и государства ошибок в книге мистера Гоббса, названной “Левиафан”» (1676).

Именно это третье сочинение лорда Кларендона и связанные с ним рассуждения А.Б. Соколова подвигли автора данной рецензии к ее написанию. Значимость этого побочного для монографии сюжета в следующем. Известно, что в советской историографии Томас Гоббс рассматривался как выдающийся философ раннего нового времени [6]. Как показала практика, концепция Гоббса об анонимном делегированном государстве обернулась «дисциплинарной» системой управления обществом. К этому выводу в ХХ в. пришел, среди прочих, М. Фуко в работе «Надзирать и наказывать» (1975). К. Скиннер, принадлежащий совсем к иной историографической традиции, говорит, собственно, об этом же в работе «Свобода до либерализма» (1998). Кларендон, знавший Гоббса лично, не мог простить ему «зла, которое он нанес королю, церкви, законам и нации» (С. 457-458). Закон и послушание, по его глубокому убеждению, вытекают «не из договора, а из обычаев предков, уважение которых является обязанностью и подданных, и власти». «В основании природы мир, и Бог... дал ему [человеку] естественную власть, чтобы управлять миром в гармонии и порядке». «Дурные люди» покусились на этот божественный миропорядок. 
Открывает монографию А.Б. Соколова пролог, в котором впервые в отечественной историографии Яков I Стюарт получает объемную характеристику как человек и государственный деятель. Он предстает как «гибкий политик», который «никогда не давал ни одной фракции установить полное господство в управлении и не становился ее инструментом» (С. 23). Конечно, были трудности, но королю удавалось сохранять согласие со своими подданными. Это и понятно: Яков VI Шотландский имел богатый опыт управления Шотландией. К слову сказать, его мать - Мария Стюарт не смогла удержать в своих руках шотландскую корону. Второй Стюарт на английском престоле, Карл I по тексту монографии выступает как прямая противоположность отцу и предстает человеком, «непригодным к монархической власти», не чувствовавшим природы «баланса» между наследственной монархией, парламентом, судебной системой и епископальной англиканской церковью.

Структурно монография поделена на семь глав в соответствии периодами жизни Эдварда Хайда, которые в значительной степени совпадают с основными вехами английской истории XVII в. Первая глава «"Высшая степень благополучия, когда-либо существовавшая”: 1608-1638» охватывает первые 30 лет жизни главного героя - будущего Лорда-канцлера Английского королевства - и дает читателю представление о его социальном происхождении и месте его семьи в ранговой иерархии английского общества. Становится ясно, что семья Хайдов не относилась к богатой титулованной аристократии (nobility), однако принадлежала к категории зажиточных землевладельцев графства Уилтшир (поместье Динтон в 13 км от Солсбери, поместье Пертон и др.). Каков был доход этих владений, А.Б. Соколов не указывает, но то, что все сыновья в семье деда, отца и самого Эдварда получили университетское образование (по преимуществу Оксфорд, колледж Св. Магдалены), говорит о состоятельности семьи. Однако средства семьи, судя по всему, формировалось не только земельными доходами. «Ограниченный сеттльмент» вынуждал младших сыновей искать доходные профессии [7. С. 181-192]. Юридическая практика открыла путь наверх как двум дядьям Эдварда, так и ему самому. Он был членом одной из четырех самых влиятельных судейских корпораций Middle Temple. В этом же «цехе» он нашел себе жену, дочь судьи сэра Томаса Эйлсбери, леди Фрэнсис. Сам же Эдвард Хайд по происхождению не был ни сэром, ни пэром, что следует из отсутствия титула в его имени.

Он относился к «сословию» джентри (С. 52). Отцу Эдварда - Генри Хайду, который сам был третьим сыном в семье, - было трудно оплачивать обучение своего третьего сына в университете. Он очень надеялся на получение стипендии, заручившись соответствующими рекомендательными письмами. Как оказалось, тщетно, но тем не менее Эдвард благополучно завершил обучение и в 1626 г. получил степень бакалавра искусств. Свободное владение латынью дало ему возможность в будущем успешно справляться с разного рода дипломатическими миссиями, другими «иностранными языками он не владел» (С. 165). Очевидно, что только благодаря личным качествам и заслугам этот человек мог сделать успешную карьеру. Вероятно, «сословная» принадлежность Хайда и была тем «обстоятельством», которое предопределило политическое фиаско лорда Кларендона в годы Реставрации. Он плохо вписывался в гедонистическую атмосферу блестящего двора Карла II, раздражая высшую аристократию своей исполнительностью, работоспособностью и следованием некогда усвоенным принципам. «Жирный стряпчий» - вот то прозвище, которое он получил в годы Реставрации.

Главным персонажем второй главы «“Ярость, неистовство, гнев”: 1638-1642» является баронет Уэнтворт (1593-1641), получивший титул графа Стаффорда в январе 1640 г. Следует согласиться с А.Б. Соколовым, что «если ключом к шотландской революции было слово «молитвенник», то ключом к английской революции стало имя Уэнтворта» (С. 89), и заметить, что впервые в отечественной историографии фигура лорда Стаффорда получает человеческие очертания. Он предстает «способным и энергичным государственным деятелем, способствовавшим стабилизации финансового и политического положения в стране в 1630-е гг.» (C. 99), успешно исполнявшим обязанности Лорданаместника Ирландии с 1633 г. и призванным короной на авансцену в тяжелый момент войны с Шотландией. Идея Стаффорда о созыве парламента в апреле 1640 г. получает по тексту монографии наименование «политики напролом», а роспуск Короткого парламента в ноябре 1640 г. вслед за текстом «Истории мятежа» интерпретируется как «роковая ошибка» Карла I, как путь к политической катастрофе (С. 95). Хотя никому тогда и в голову не могло прийти, что через несколько месяцев - в мае 1641 г. - Стаффорд будет казнен.

Здесь для исследователя один из трудных моментов в интерпретации политической биографии главного героя - члена палаты общин Короткого и Долгого парламентов, так как, «по-видимому, Хайд голосовал за билль, провозглашавший Стаффорда виновным в государственной измене, однако в этом не признался» (C. 100). А.Б. Соколов показывает, что Стаффорд фактически оказался в одиночестве и между двух огней. С одной стороны, это были радикальные реформаторы во главе с Пимом и Гемпденом, с другой - группировка «конституционных монархистов», в которую входили сам Хайд и его патрон лорд Фолкленд. В «Истории мятежа» лорд Кларендон так интерпретировал трагедию лорда Стаффорда: «Его несчастье состояло в том, что он привлек лишь очень немногих мудрых людей, и не было ни одного... чьи возможности и способности были равны ему... Его доминирующей страстью была гордость... ему вполне подходит эпитафия, которую... Сцилла написал самому себе: "Никто не превосходил его в том, чтобы делать добро своим друзьям и наносить вред своим врагам". - И то и другое было хорошо известно и получило недобрую славу» (С. 101). А.Б. Соколов приводит меткий эпиграф к сочинению о лорде Стаффорде, появившемуся после его кончины: «Каждому в назидание лорда Уэнтворта пример; Есть шанс упасть, взобравшись вверх без мер» (C. 101). Но самое главное, и это прочитывается как вывод А.Б. Соколова: Стаффорда предал король, по- 
лагая, что это будет последняя жертва на алтарь парламента.

Главным «персонажем» третьей и четвертой глав является гражданская война как сложный многоуровневый социально-политический феномен. По прочтении этих глав читатель уже готов разделить точку зрения ревизионистов о революции как историографическом мифе. Действительно, здесь действовало множество самодостаточных тенденций, которые в какие-то моменты вступали в противоречия, а где-то сливались в единый поток событий и обстоятельств. Это и «Война трех королевств», и «Война Короля и Парламента», и противостояние «Двора и Страны» и т.д. Событийнохронологический подход позволяет автору нанизать эти «бусины» случайностей, совпадений, личных амбиций, групповых интересов в связное, но трудное для чтения повествование. Собственно, самому Эдварду Хайду уделено здесь не так много внимания, зачастую приводятся его позднейшие оценки тем или иным событиям 1642-1649 гг.

Из третьей главы «“Противоестественная война”: 1642-1645» мы узнаем, что уже в феврале 1642 г. Эдвард Хайд присоединился к покинувшему Лондон королю, оказавшись, соответственно, в «списке» врагов парламента. Принятие «Великой ремонстрации» (ноябрь 1641 г.), против которой Хайд открыто выступил в палате общин, окончательно определило его выбор. Именно этот момент стал решающим в его карьере. Он был достаточно молодым (34 года), но уже опытным политиком, имел «юридический склад ума, твердую уверенность в правильности своего мнения и чутье к государственным делам» (С. 130). Прибыв в Оксфорд, Хайд становится неформальным советником короля. Вскоре последний пожалует ему титул рыцаря и введет в состав Тайного совета. В марте 1642 г. он получит назначение на пост канцлера казначейства (Chancellor of the Exchequer) (С. 165), т.е. неблагодарную работу по сбору налогов и пополнению королевской казны в условиях военного времени. В этой главе показано, как этому «исполнительному и проницательному человеку», приходилось маневрировать между различными группировками вокруг короля - от круга королевы Генриетты-Марии, не любившей его за недоверие к французам, до группировки «людей меча» во главе с принцем Рупертом. А.Б. Соколов приходит к выводу, что с этого времени Эдвард Хайд фактически становится теоретиком и идеологом роялистского лагеря.

Твердая позиция Хайда принудить парламент к миру, найти компромисс в переговорах 1645 г. фактически предопределила его «почетную» отставку - король принял решение в целях безопасности разделиться с наследником престола принцем Чарльзом и назначил Эдварда Хайда сопровождать его на остров Джерси, где они пробудут около двух лет (С. 198). Собственно прелюдии и событиям Второй гражданской войны посвящена четвертая глава «“Когда вся нация погрязла во грехе": 1645-1649». Для Хайда, игравшего теперь ключевую роль в защите настоящих и будущих интересов наследника английского престола, это было время, когда он начал писать «Историю мятежа» и «Размышления о псалмах Давида». Под давлением мрачных предчувствий он стремится осмыслить произошедшее, видит в этом исполнение своего гражданского долга. Да и принц Уэльский уходит из-под его прямой опеки в ситуации роялистских мятежей 1648 г. в Южном Уэльсе, Кенте, став главнокомандующим флотом, обретя, таким образом, мобильность на море. Провал роялистов заставляет Карла I настаивать на том, чтобы принц покинул Британию. Выбор наследника престола симптоматичен - он обосновывается в Голландии, самом свободном и экономически процветающем государстве Европы того времени. Хайд по прямому указанию короля и Генриетты-Марии летом 1648 г. покидает Джерси и соединяется с принцем в Гааге в сентябре 1648 г. Казнь Карла I в январе 1649 г. сделала Хайда в одночасье членом Тайного совета короля в изгнании.

Хайд, всегда сторонившийся военных дел, не был тесно связан с попытками Карла II вернуть трон в 1649-1651 гг. Он не поддерживал провалившуюся идею «похода» в Шотландию (С. 276-279), хоть Карл II и был официально коронован в аббатстве Скон в Пертшире в январе 1651 г. Только после всех этих неудач король сделает ставку на Хайда, который становится его главным советником с 1652 г.

Пятая глава «“Отдать сердце целиком выздоровлению Англии”: 1649-1660» вводит нас в круг обязанностей Эд. Хайда в годы иммиграции. В центре повествования этой главы оказывается европейский контекст политики «кабинета» короля-изгнанника. В нем Хайд неформально продолжает исполнять обязанности канцлера казначейства. Смерть Вильгельма II Оранского, на чье гостеприимство и дипломатическую поддержку в Голландии опирался Карл II, от оспы в ноябpe 1650 г. нанесла «роковой удар» - под давлением Генеральных штатов английский король был вынужден искать себе новое пристанище. Переезд «двора» в Версаль оказался неизбежным. Помощь французского двора в ситуации Фронды и продолжающейся войны с Испанией ограничилась скудным содержанием королевы-матери и короля. Экономить приходилось на всем. Некоторым утешением для Хайда стала приехавшая к нему семья - жена и четверо детей, которых он предпочел разместить подальше от Гааги, в Антверпене (C. 259).

Однако в 1654 г. ситуация принципиально изменилась. Голландия примирилась с Республикой Кромвеля и признала Навигационный акт. Кромвель подписал договоры о дружбе со Швецией, Данией, Португалией, что поставило Республику на грань войны с Испанией. Условием примирения Кромвеля с кардиналом Мазарини стало «изгнание Карла II из Франции» (С. 293). Карл II, который не знал куда ему теперь следовать, покинул Францию в июле 1654 г. Неожиданно для себя он встретил радушный прием в германских землях. Кельн, «красиво расположенный на берегах Рейна», стал его прибежищем на последующие полтора года. К счастью для Карл II, начавшаяся в 1654 г. англо-испанская война улучшила его положение. Он получил покровительство Филиппа IV Испанского, и местом его резиденции стал Брюгге. Оставалось ждать, «когда по воле Бога наступит подходящее время». Эту 
позицию в окружении короля твердо отстаивал провиденциалист Эдвард Хайд, назначенный королем на должность Лорда-канцлера Казначейства в январе 1658 г. А.Б. Соколову удалось показать, что смерть Кромвеля осенью 1658 г. сама по себе отнюдь не открывала Карлу II «дороги» на родину. Ряд королевских деклараций, подготовленных Хайдом и обнародованных задолго до 1660 г., обеспечил возможность воцарения Стюартов на английском престоле. В них был зафиксирован принцип «о прощении всем, кроме тех, кто проголосовал за лишение жизни Карла I» (С. 299). Именно Хайд все эти годы твердо держался принципа восстановления Карла II как законного монарха на престоле и готов был обещать «терпимость всем миролюбиво настроенным мирянам» (С. 321). Эти принципы и были положены в основу Бредской декларации 1660 г. Реставрация монархии произошла законным путем, и заслуга в этом во многом принадлежала Эдварду Хайду.

По логике вещей, глава шестая «“Канцлер с человеческим сердцем”: 1660-1667» должна была бы носить кульминационный характер. Сбылись чаяния главного героя - Стюарты счастливо вернулись на английский престол. Карл II готов был следовать советам своего лорда-канцлера, щедро вознаградив его землями и титулом лорда Кларендона в 1661 г. (С. 336). Однако А.Б. Соколов выбирает другую стратегию - он стремится реконструировать ряд обстоятельств, приведших к падению лорда Кларендона - импичменту 1667 г. Это чума 1665 г., Великий пожар в Лондоне, экстраординарные расходы в англо-голландской войне 16651667 гг. (против которой Кларендон выступал). Лично лорду-канцлеру в вину вменялись: выбор в жены Карлу II бесплодной португальской принцессы Екатерины Браганца (якобы чтобы обеспечить престол детям своей дочери Анны, герцогини Йоркской); продажа Дюнкерка Людовику XIV в 1662 г. (надо заметить, вынужденная акция, предпринятая для залатывания «дыр» в королевской казне); нежданные финансовые издержки на гарнизон, перемещенный из Дюнкерка в Танжер (полученный в качестве приданного за Екатериной Браганца в 1662 г.). Несомненно, с самого начала Реставрации финансовый вопрос были одним из самых острых (С. 362-363). Любопытно упоминание в этой главе о личной заинтересованности короля и его брата герцога Йоркского во Второй англо-голландской войне как пайщиков Африканской компании (С. 382). Интересно, что знаменитый Кодекс Кларендона интерпретируется А.Б. Соколовым как дело рук Кавалерского парламента - вывод, обладающий очевидной новизной в отечественной историографии (С. 368-373). То есть, как выясняется, Кларендону пришлось уступить в религиозном вопросе и фактически порвать «с духом толерантности Бредской декларации» (С. 368). Любопытным также является внимание к судьбам еще живых к 1660 г. 38 человек из 59, чьи подписи стояли под смертным приговором Карлу I (С. 347-361).

В короткой седьмой главе «"Приноравливаясь к судьбе”: 1667-1674» автор с большим сочувствием описывает скитания старого больного человека на чужбине - Кларендон был вынужден, дабы не повто- рить судьбу лорда Стаффорда, бежать во Францию в ноябре 1667 г. Он завершает свой жизненный путь в Руане в 1774 г., соборованный англиканским священником и в окружении вызванных к нему старших сыновьей (есть документальные свидетельства о присутствии только Лоуренса).

Подводя в эпилоге итоги, А.Б. Соколов останавливается на «конфликте» интерпретаций вокруг наследия лорда Кларендона. Он выделяет традиционные два направления - «вигское» и «торийское». В рамках третьего направления, а мы не должны упускать из внимания марксистскую историографию, Эдвард Хайд остается антигероем и не удостаивается хоть скольконибудь серьезного внимания. Автор показывает, что критический подход к наследию Хайда сохраняли историки вигского направления С. Гардинер, Г. Галлам, Ч. Фирд, Р. Хаттон. Занимавшие пропарламентские позиции, они считали его консервативным роялистом, а также указывали на отсутствие объективности и оригинальности труда «Истории мятежа». Историки консервативной школы Бр. Уолмолд, Х. Тревор-Ропер, Р. Харрис видели в Кларендоне автора новой теории «смешанной монархии», считая его защитником конституционных свобод и предшественником Эд. Берка, Д. Юма и Э. Гиббона (С. 448). Самым цитируемым по всей монографии является, пожалуй, историк Р. Оллард, который, как кажется, близок к ревизионистам К. Расселу, Дж. Моррилу.

А что же сам Андрей Борисович? Выбор героя, угол зрения на события Английской революции из роялистского лагеря указывают на его предпочтения. С большой симпатией он пишет о Кларендоне как человеке твердых принципов и «золотой середины», предпочитающем решать дела мирным путем. Главной заслугой Кларендона, что становится ясно по прочтении монографии, было сохранение Карла II и его двора в годы иммиграции и обеспечение легального восхождения династии Стюартов на английский престол.

Формирование прочной конституции - «король и парламент должны взаимодействовать на основе доверия и обоюдной зависимости» (С. 333) - вот, что было главной заботой Кларендона в первые годы Реставрации. Это-то и сделало его ее «балластом». До Славной революции было еще больше десяти лет конституционных опытов и борьбы за «толерантность». В своих сочинениях, да и поступках, лорд Кларендон предстает убежденным носителем идеи божественного порядка. Обвинения в его коррумпированности выглядят крайне неубедительными, так как он вел достаточно скромный образ жизни (правда, собирал книги и картины). Его «большой ошибкой», как признавал он сам, было строительство Кларендон-хауза в Лондоне. Стоимость особняка, к большому его огорчению, превысила первоначальную смету в три раза. Когда он «отправился с изгнание, сумма его долгов превышала сто тысяч фунтов» стерлингов (С. 444). Покаяние его также было обращено к семье, которой он «не уделял того внимания, которое она заслуживала, хотя тому много оправданий» (С. 461).

Да, Кларендон был призван служить Отечеству «верой и правдой». Его политическое кредо опиралось 
на устойчивые моральные принципы. Христианская мораль и принципы законности были непреложным правилом руководства в его суждениях и поступках. Добродетель, терпение, взвешенный подход - вот в чем для него был залог устойчивости политической перспективы. Пример Эдварда Хайда позволяет поднять вопрос об этике и морали в политике (в противовес концепции Макиавелли об ее аморальности). М. Вебер в новейшее время одним из первых поднял этот вопрос, указав на то, что отсутствие морали в политике оборачивается необходимостью применения силы [8,
С. 693-697]. Процветание отечества и поиск компромиссов в строительстве общего дома - вот чему должны служить сообща лучшие и самые достойные мужи государства. Не зря Кларендон ценил выше других человеческих чувств мужскую дружбу, которую считал истинным воплощением близости и добродетели (C. 178, 439). А что же до брака его дочери с будущим королем Англии Яковом II и двух его внучек, ставших в будущем королевам Англии, об этом читайте замечательную во многих отношениях книгу Андрея Борисовича Соколова «Кларендон и его время».

\section{ЛИТЕРАТУРА}

1. Соколов А.Б. Навстречу друг другу. Россия и Англия в XVI-XVIII вв. Ярославль. 1992.

2. Соколов А.Б. Интервью с Р. Козеллеком // Диалог со временем : альманах интеллектуальной истории. М. : ИВИ РАН, 2005. № 15. С. 326-340.

3. Соколов А.Б. Интервью с Х. Уайтом // Диалог со временем : альманах интеллектуальной истории. М. : ИВИ РАН, 2005. № 14. С. $335-346$.

4. Соколов А.Б. Школьный учебник истории в Соединенных Штатах Америки. Монография. Ярославль: ЯГПУ, 2011.

5. Ямпольский М.Б. Сообщество одиночек: Арендт, Беньямин, Шолем, Кафка // Новое литературное обозрение. 2004. № 67. С. 78-105.

6. Мееровский Б.В. Гоббс. М. : Мысль, 1975.

7. Созинова К.А. Романы о наследстве: английское общество и традиционное землевладение на рубеже XVIII-XIX вв. (на примере творчества Джейн Остен) // Диалог со временем : альманах интеллектуальной истории. М. : ИВИ РАН, 2005. № 52.

8. Вебер М. Политика как призвание и профессия : избранные произведения. М. : 1990. С. 693-697.

Vysokova Veronika V. Ural Federal University (Yekaterinburg, Russian Federation) E-mail: vyssokova@mail.ru

LORD CLARENDON, OR REASONING ON POLITICAL MORALITY. REVIEW OF: SOKOLOV A.B. KLARENDON I YEGO VREMYA. STRANNAYA ISTORIYA EDVARDA KHAYDA: KANTSLERA I IZGNANNIKA [CLARENDON AND HIS TIME. THE STRANGE STORY OF EDWARD HYDE: CHANCELLOR AND EXILE]. SPb. : ALETHEIA, 2017. 472 p.

Keywords: English revolution of the 17th century; T. Hobbes; Lord Clarendon; political morality; Stuarts; Ed. Hyde.

This review considers a new monograph entitled "Clarendon and His time. The Strange Story of Edward Hyde: Chancellor and Exile" by A.B. Sokolov, Dr. Hab. (History), Dean of the Faculty of History, Yaroslavl State Pedagogical University named after K.D. Ushinsky. The review focuses on the analysis of a new approach in the study of the English revolution of the 17th century in Russian historiography - through the intellectual biography of Ed. Hyde A.B. Sokolov gives the interpretation of the ideology of the royalist camp and its leaders. The review is structured according to the seven chapters of the monograph by A. Sokolov and the main periods of the life of Lord Clarendon. The Lord Chancellor is shown, on the one hand, as an outstanding royalist politician of the English Revolution, who ensured the legitimate accession of the Stuarts to the English throne in 1660, on the other hand, as one of the most important historians of England, as author of the most influential contemporary history of the Civil War "The History of the Rebellion". This historical work of Lord Clarendon became the main historical source in the pre-review's monograph - A.B. Sokolov focused on what about the author of "The History of the Rebellion" kept silent. This action of investigating a wide portrait gallery of contemporaries of Ed. Hyde Sokolov makes a conclusion about the Clarendon's omissions and subjective interpretations of the events of the English revolution XVII century. The review shows that A.B. Sokolov pays special attention to the reconstruction of the circumstances that led to the fall of Lord Clarendon - the impeachment of 1667. It is interesting that the famous Clarendon Code is interpreted by A.B. Sokolov as the work of the Cavaliers Parliament, - this conclusion has an obvious novelty in historiography, i.e. it is shown that Clarendon had in fact was forced to break with the spirit of tolerance of the Declaration of Breda. A.B. Sokolov considers the "conflict" of interpretations around the heritage of Lord Clarendon. He fixes the traditional two directions - "Whigs" and "Tory" and shows that in the framework of the third Marxist historiography Edward Hyde remains an anti-hero. The monograph shows that the historians of the Whigs historiography S. Gardiner, H. Gallam and others maintained a critical approach: they considered him a conservative royalist and evaluate negatively. Historians of the conservative school H. Trevor-Roper, R. Harris and others saw in Clarendon the author of a modern theory of "mixed monarchy", considering him a defender of constitutional freedoms and a predecessor of Ed. Burke, D. Hume and E. Gibbon. The most quoted throughout the monograph is the historian R. Ollard, who is close to the revisionists C. Russell, J. Morrill. Following them A.B. Sokolov writes about Clarendon with great sympathy as a man of solid principles who prefers to solve matters peacefully. Thus, we can talk about the "glorious revolution" in Russian historiography - A.B. Sokolov finally shifts the focus of attention from representatives of the left camp of the "English bourgeois revolution" to the camp of the gentlemen-royalists.

\section{REFERENCES}

1. Sokolov, A.B. (1992) Navstrechu drug drugu. Rossiya i Angliya v XVI-XVIII vv. [Towards each other. Russia and England in the 16th - 18th centuries]. Yaroslavl: Yaroslavl State Pedagogical University.

2. Sokolov, A.B. (2005a) Interv'yu s R. Kozellekom [Interview with R. Kosellek]. Dialog so vremenem-Dialogue with Time. 15. pp. 326-340.

3. Sokolov, A.B. (2005b) Interv'yu s Kh. Uaytom [Interview with H. White]. Dialog so vremenem-Dialogue with Time. 14. pp. 335-346.

4. Sokolov, A.B. (2011) Shkol'nyy uchebnik istorii v Soedinennykh Shtatakh Ameriki [School history textbook in the United States of America]. Yaroslavl: Yaroslavl State Pedagogical University.

5. Yampolsky, M.B. (2004) Soobshchestvo odinochek: Arendt, Ben'yamin, Sholem, Kafka [The Community of Singles: Arendt, Benjamin, Scholem, Kafka]. Novoe literaturnoe obozrenie. 67. pp. 78-105.

6. Meerovsky, B.V. (1975) Gobbs [Hobbes]. Moscow: Mysl'.

7. Sozinova, K.A. (2015) Inheritance novels: English society and traditional English landownership in the late 18th - early 19th centuries (Jane Austen's novels). Dialog so vremenem - Dialogue with Time. 52. (In Russian).

8. Weber, M. (1990) Politika kak prizvanie i professiya. Izbrannye proizvedeniya [Politics as a vocation and profession. Selected Works]. Translated from German. Moscow: Progress. pp. 693-697. 